American J. of Engineering and Applied Sciences 3 (2): 433-440, 2010

ISSN 1941-7020

(C) 2010 Science Publications

\title{
A Novel Linear Switched Reluctance Machine: Analysis and Experimental Verification
}

\author{
${ }^{1}$ N.C. Lenin and ${ }^{2}$ R. Arumugam \\ ${ }^{1}$ Department of Electrical Engineering, St. Joseph's College of Engineering, Chennai, India \\ ${ }^{2}$ Department of Electrical Engineering, SSN College of Engineering, Chennai, India
}

\begin{abstract}
The important problems to be solved in Linear Switched Reluctance Machines (LSRMs) are: (1) to design the shape and size of poles in stator and translator cores; (2) to optimize their geometrical configuration. A novel stator geometry for LSRMs that improved the force profile was presented in this study. In the new geometry, pole shoes were affixed on the stator poles. Static and dynamic characteristics for the proposed structure had been highlighted using Two Dimensional (2-D) Finite Element Analyses (FEA). Motor performance for variable load conditions was discussed. The finite element analyses and the experimental results of this study proved that, LSRMs were one of the strong candidates for linear propulsion drives. Problem statement: To mitigate the force ripple without any loss in average force and force density. Approach: Design modifications in the magnetic structures. Results: 2-D finite element analysis was used to predict the performance of the studied structures. Conclusion/Recommendations: The proposed structure not only reduces the force ripple, also reduced the volume and mass. The future study is to make an attempt on vibration, thermal and stress analyses.
\end{abstract}

Key words: Linear switched reluctance motor, finite element analysis, force ripple, force density

\section{INTRODUCTION}

Linear switched reluctance motors are an attractive alternative to linear induction or synchronous machines due to lack of windings on the stator or translator structure, easier manufacturing and maintenance, good fault tolerance capability (Miller, 1993). LSRMs are classified as (a) longitudinal flux (b) transverse flux. This study is dedicated to the longitudinal flux LSRM. A design procedure for longitudinal-flux LSRM has been described in (Byeong-Seok et al., 2000). Other types of longitudinal-flux LSRMs are presented in (Chayopitak and Taylor, 2005), with coupled flux paths and in (Sun et al., 2008) with uncoupled flux paths for a magnetic levitation system. A high force longitudinalflux double-sided double-translator LSRM has been analyzed in (Deshpande et al., 1995). Longitudinal-flux LSRMs have been proposed for applications such as precise motion control (Pan et al., 2005; Zhao et al., 2007) and as propulsion systems for railway vehicles (Kolomeitsev et al., 2008) or vertical elevators (Lim and Krishnan, 2007; Lim et al., 2008; Lobo et al., 2008). Recently, a detailed sensitivity analysis of double sided LSRM parameters based on (Arumugam et al., 1988) has been presented in (Amoros and Andrada, 2010).

In despite of the various advantages, LSRMs has some drawbacks such as high force ripple, vibration, acoustic noise and need of power electronic converters. Several efforts to reduce or eliminate the torque ripple of the Rotary Switched Reluctance Motors (RSRMs) have been presented in the literature (Schramm et al., 1992; Hussain and Ehsani, 1996; Rabinovici, 2005). Multi phase excitation to reduce the force ripple in the LSRM has been explained in (Bae et al., 2000). However, the previous method considerably increases the copper losses. In this study a novel stator structure for a longitudinal flux LSRM is proposed to reduce the force ripple.

A control strategy for the proposed LSRM is dynamically simulated, which consists of force and velocity control loops. A trapezoidal velocity profile is used to control travel position smoothly during acceleration, deceleration and stop of the motor. Conventional proportional-integral controller is used for the current and velocity control loops (Lim et al., 2008).

\section{MATERIALS AND METHODS}

Force ripple analysis using an alternative geometry: Definition, sources of the force ripple and techniques to reduce it: Assuming that the maximum value of the static force as $F_{\max }$, the minimum value that occurs at the intersection point of two consecutive phases as $F_{\text {min }}$ and the average force as $F_{\text {avg }}$, the percentage force ripple may be defined as:

Corresponding Author: N.C. Lenin, Department of Electrical Engineering, St. Joseph's College of Engineering, Chennai, India 
Force ripple $(\%)=\frac{F_{\max }-F_{\text {min }}}{F_{\text {avg }}} \times 100$

The causes of the force ripple in LSRMs are mainly due to the switching of phase currents into its windings and the highly nonlinear nature of the phase inductance variation when the translator moves. These force pulsations contribute to vibrations and acoustic noise in LSRMs. There are two approaches to force profile improvement. One approach is to suitably shape the input excitation current profile by using an electronic control of the power controllers. The second approach is to modify the geometry of the poles of the stator and translator. This research makes an attempt to examine the force profile by the geometry modifications approach, by providing pole shoes on the stator poles.

Effect of stator pole shaping on the force profile: This sensitivity study aims mainly to determine the improvement in the force profile when the stator pole width gets varied. The conventional LSRM which is considered in this study is shown in Fig. 1. The specifications of the conventional machine are given in Table 1.

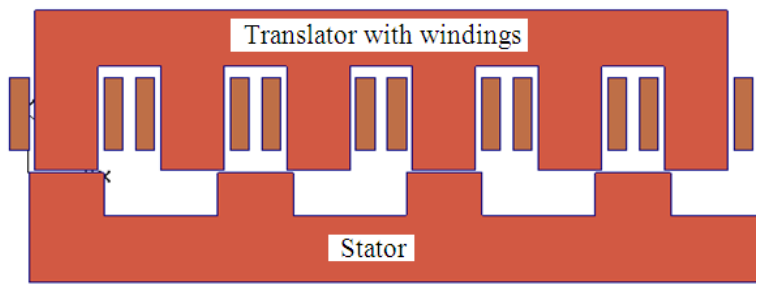

Fig. 1: 2D cross sectional view of the conventional LSRM

Table 1: Specifications and dimensions of the studied LSRM

$\mathrm{l}_{\mathrm{g}}=1.5 \mathrm{~mm}$

$\mathrm{F}_{\max }=120 \mathrm{~N}$

$\mathrm{L}_{\text {stack }}=40 \mathrm{~mm}$

Steel type (stator)-M 45

Steel type (translator)-M 45

Travel length $=2 \mathrm{~m}$

$\mathrm{V}_{\text {rated }}=120 \mathrm{~V}$

$\mathrm{I}_{\text {rated }}=10 \mathrm{~A}$

$\mathrm{N}_{\mathrm{ph}}=396$

$\mathrm{w}_{\mathrm{sp}}=21 \mathrm{~mm}$
$\mathrm{~h}_{\mathrm{sp}}=30 \mathrm{~mm}$
$\mathrm{w}_{\mathrm{sy}}=35 \mathrm{~mm}$
$\mathrm{w}_{\mathrm{ss}}=31 \mathrm{~mm}$
$\mathrm{~W}_{\mathrm{ts}}=26 \mathrm{~mm}$
$\mathrm{~h}_{\mathrm{tp}}=48 \mathrm{~mm}$
$\mathrm{w}_{\mathrm{tp}}=13 \mathrm{~mm}$
$\mathrm{w}_{\mathrm{ty}}=30 \mathrm{~mm}$
Wire size = AWG 18

Table 2: Comparison of force ripple for various stator pole widths (without pole shoes)

\begin{tabular}{lllllrl}
\hline $\mathrm{W}_{\text {sp }}(\mathrm{mm})$ & $\mathrm{F}_{\min }(\mathrm{N})$ & $\mathrm{F}_{\max }(\mathrm{N})$ & $\mathrm{F}_{\text {avg }}(\mathrm{N})$ & Ripple $(\%)$ & $\mathrm{L}_{\min }(\mathrm{H})$ & $\mathrm{L}_{\max }(\mathrm{H})$ \\
\hline 16 & 67.33 & 124.87 & 100.39 & 60.38 & 0.02972 & 0.08626 \\
17 & 67.91 & 124.70 & 101.07 & 57.68 & 0.03019 & 0.08658 \\
18 & 68.23 & 124.57 & 101.10 & 55.88 & 0.03071 & 0.08683 \\
19 & 68.32 & 124.11 & 101.30 & 53.41 & 0.03125 & 0.08700 \\
20 & 68.28 & 124.34 & 100.86 & 56.16 & 0.03184 & 0.08713 \\
21 & 67.88 & 123.90 & 100.63 & 55.67 & 0.03246 & 0.08725 \\
\hline
\end{tabular}

The width of the stator pole is varied from 16-21 $\mathrm{mm}$ in steps. The translator geometry remains unchanged throughout the sensitivity study. The height of the stator pole is fixed. The field analysis has been carried out for a phase excitation of $10 \mathrm{~A}$. The predicted propulsion force, normal force, inductance profiles and average force are shown in Fig. 2. Table 2 summarizes the comparison of the studied configurations.

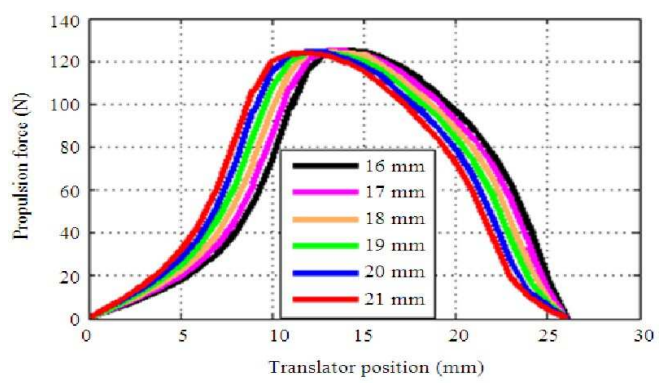

(a)

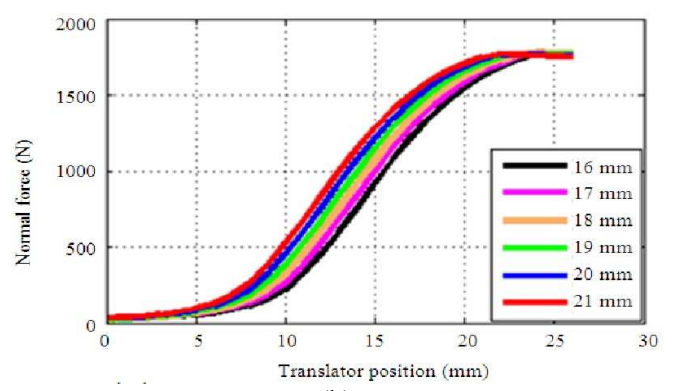

(b)

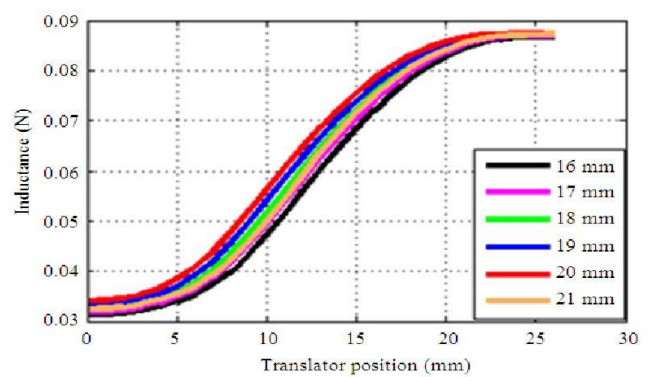

(c)

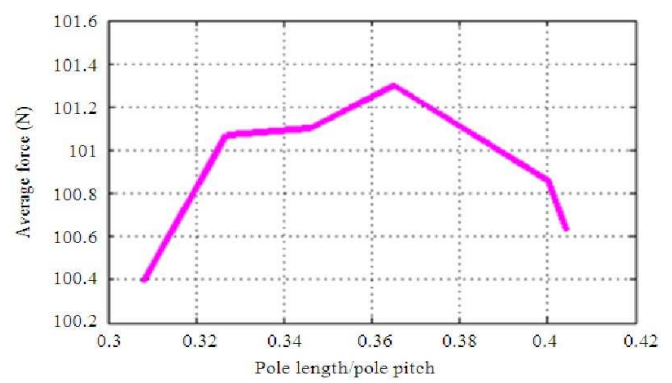

(d)

Fig. 2: Force and Inductance for various stator pole widths (without pole shoes) 
From the Table 2 it can be observed that, when the stator pole width is increased, there is a reduction in the average force, which is not large after a certain point. Figure 2d shows the stator pole length/pole pitch Vs average force. From Fig. 2d, we inferred that, the maximum average force and the low force ripple occurs, when the pole width is $19 \mathrm{~mm}$.

Force ripple minimization using stator pole shoes: Improving the force profile using stator pole shoes is investigated by a 2-D finite-element analysis. The difference between the conventional and the proposed stator poles are shown in Fig. 3. The cross sectional view of the proposed LSRM with pole shoes is shown in Fig. 4. The analysis is carried out on the conventional LSRM with a pole shoe, which is affixed on the stator poles. The width of the stator pole shoe is $4 \mathrm{~mm}$. The stator pole width is varied from $16-20 \mathrm{~mm}$ in steps. The width of the pole shoe and overall height of the stator pole are maintained constant. The mutual inductance and leakage effects are neglected. The simulation is presented for an excitation current of $10 \mathrm{~A}$.

The predicted propulsion force, normal force, inductance profiles and the average force are shown in Fig. 5. Table 3 summarizes the comparison of the studied configurations with pole shoes. The stator volume, stator mass and the \% force ripple reduction are compared in Table 4. Figure $5 \mathrm{~d}$ shows the stator pole length/pole pitch vs. average force. From Fig. 6, the maximum average force occurs when the stator pole width is $19 \mathrm{~mm}$ with a $4 \mathrm{~mm}$ pole shoe.

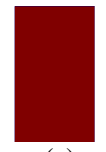

(a)

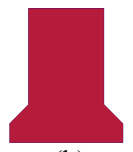

(b)
Fig. 3: (a) Conventional; (b) Proposed

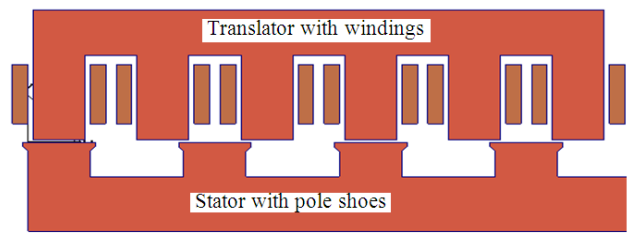

Fig. 4: 2D cross sectional view of the proposed LSRM

Table 3: Comparison of force ripple for various stator pole widths (with pole shoes)

\begin{tabular}{|c|c|c|c|c|c|c|}
\hline $\mathrm{W}_{\mathrm{sp}}(\mathrm{mm})$ & $F_{\min }(\mathrm{N})$ & $\mathrm{F}_{\max }(\mathrm{N})$ & $\mathrm{F}_{\mathrm{avg}}(\mathrm{N})$ & Ripple $(\%)$ & $\mathrm{L}_{\min }(\mathrm{H})$ & $\mathrm{L}_{\max }(\mathrm{H})$ \\
\hline 16 & 69.30 & 123.33 & 100.20 & 53.97 & 0.03130 & 0.08681 \\
\hline 17 & 68.83 & 122.76 & 100.74 & 53.54 & 0.03194 & 0.08708 \\
\hline 18 & 68.84 & 122.18 & 100.72 & 52.95 & 0.03260 & 0.08723 \\
\hline 19 & 68.62 & 121.78 & 100.98 & 52.64 & 0.03327 & 0.08730 \\
\hline 20 & 68.27 & 121.77 & 100.70 & 53.12 & 0.03403 & 0.08737 \\
\hline
\end{tabular}

During starting, the deceleration command is given at $0.5 \mathrm{~m}$ and during stopping; the deceleration command is given at $0.1 \mathrm{~m}$. The duration for holding at the stop position is set to $1 \mathrm{sec}$. Figure 7 shows the simulation results of the position, velocity, phase current and generated force of the LSRM at $0.15 \mathrm{~m} \mathrm{sec}^{-1}$.

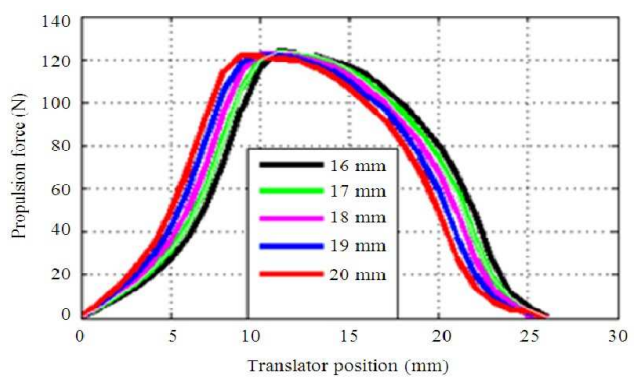

(a)

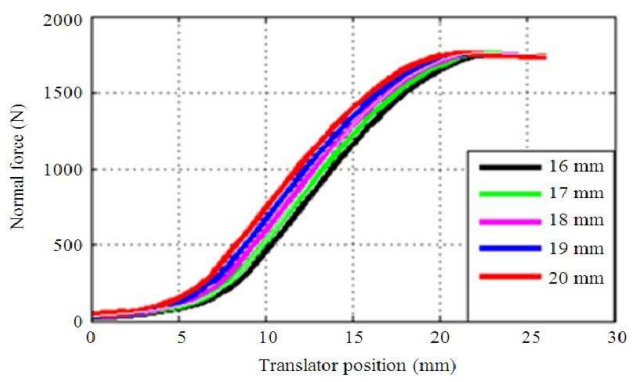

(b)

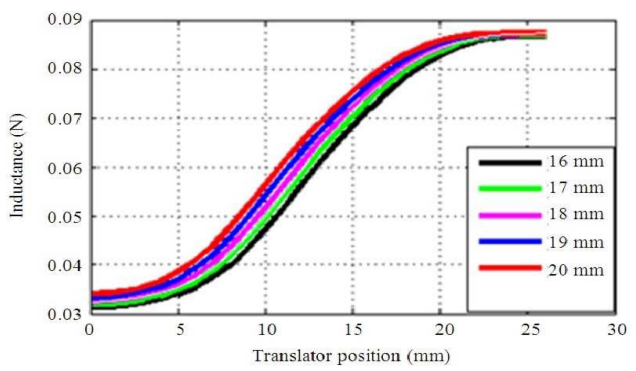

(c)

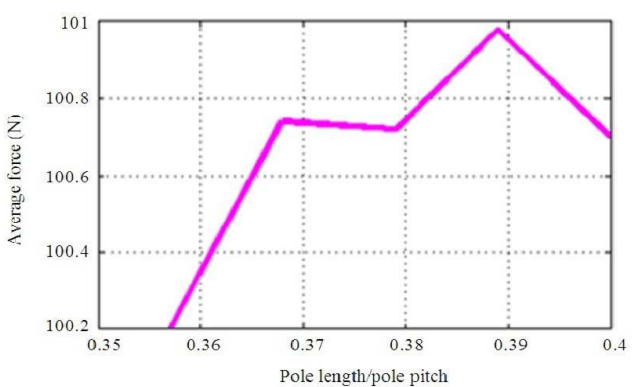

(d)

Fig. 5: Force and inductance for various stator pole widths (with pole shoes) 


\section{Dynamic simulation:}

Force and current control: For a vertical or horizontal applications, the LSRMs needs a precise control strategy consisting of force, current, velocity and position controls, as shown in Fig. 6. Force control with a Force Distribution Function (FDF) is used to control the LSRM. A trapezoidal velocity profile is used to obtain the desired response curve of the position. In addition, current and velocity controls with Proportional-Integral (PI) control for the proposed LSRM are explained. The proposed LSRM is simulated at $0.15 \mathrm{~m} \mathrm{sec}^{-1}$ velocity. The data for the dynamic simulation is obtained from the FEA, which is shown in Fig. 5. The remaining motor parameters and input specifications are summarized in the Table 1.

In Fig. 7a the designed LSRM successfully carries the load at $0.15 \mathrm{~m} \mathrm{sec}^{-1}$ producing an excellent velocity and position control performance. After the deceleration command is given at 0.5 and $0.1 \mathrm{~m}$ during starting and stopping respectively, the motor stops at 0.49 and $0.1 \mathrm{~m}$, where the velocity command from the velocity profile is zero. Under continuous operation, the current amplitude values in starting and stopping are 9.6 and $8.4 \mathrm{~A} /$ phase, respectively. In addition, the

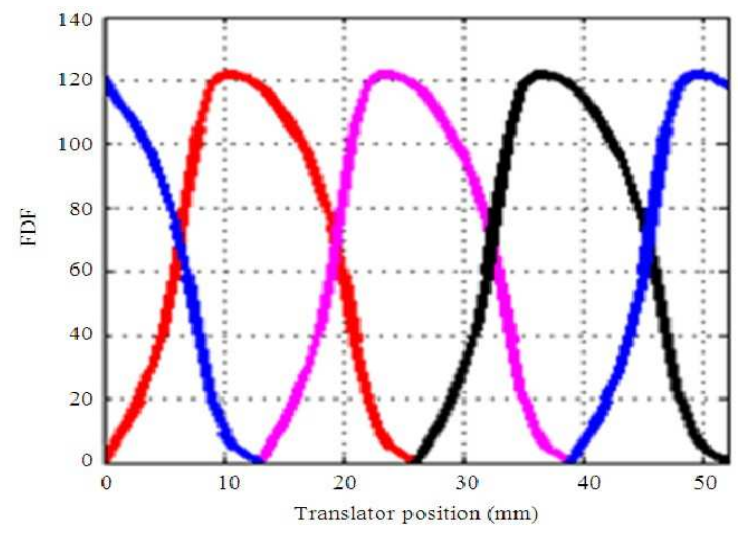

average force produced is $119.7 \mathrm{~N}$ during acceleration and $113.6 \mathrm{~N}$ during deceleration.

Table 4: Comparison of volume, mass and force ripple

\begin{tabular}{|c|c|c|c|c|c|}
\hline \multirow[b]{2}{*}{$\begin{array}{l}W_{\mathrm{sp}} \\
(\mathrm{mm})\end{array}$} & \multicolumn{2}{|l|}{ Volume $\left(\mathrm{m}^{3}\right)$} & \multicolumn{2}{|l|}{ Mass $(\mathrm{kg})$} & \multirow{2}{*}{$\begin{array}{l}\text { Force } \\
\text { ripple } \\
\text { reduction } \\
(\%)\end{array}$} \\
\hline & $\begin{array}{l}\text { Without pole } \\
\text { shoes }\end{array}$ & $\begin{array}{l}\text { With pole } \\
\text { shoes }\end{array}$ & $\begin{array}{l}\text { Without pole } \\
\text { shoes }\end{array}$ & $\begin{array}{l}\text { With pole } \\
\text { shoes }\end{array}$ & \\
\hline 16 & 0.00243 & 0.00238 & 18.68 & 18.37 & 10.62 \\
\hline 17 & 0.00245 & 0.00242 & 18.88 & 18. & 7.18 \\
\hline 18 & 0.002 & 0.00245 & 19.10 & 18.92 & 5.24 \\
\hline 19 & 0.00250 & 0.00249 & 19.28 & 19.19 & 1.44 \\
\hline 20 & 0.00253 & 0.00252 & 19.48 & 19.46 & 5.41 \\
\hline 21 & 0.00255 & NA & 19.67 & NA & NA \\
\hline
\end{tabular}

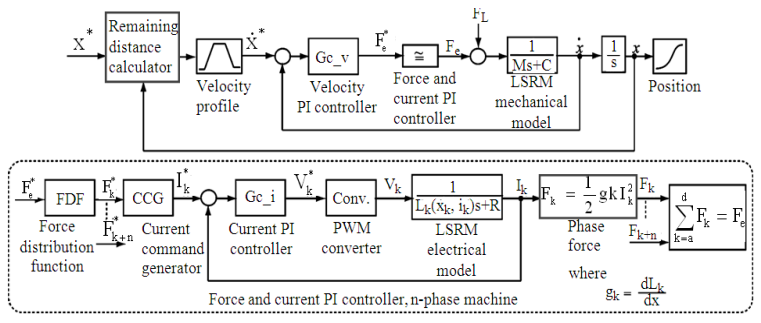

Fig. 6: Control block diagram for the proposed LSRM

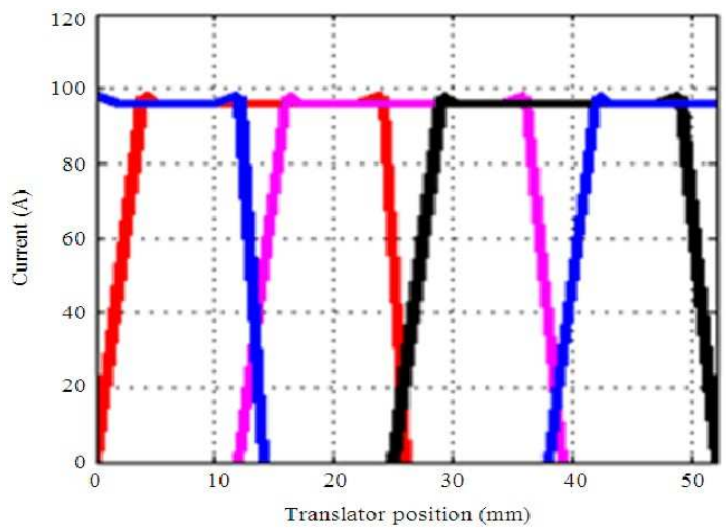

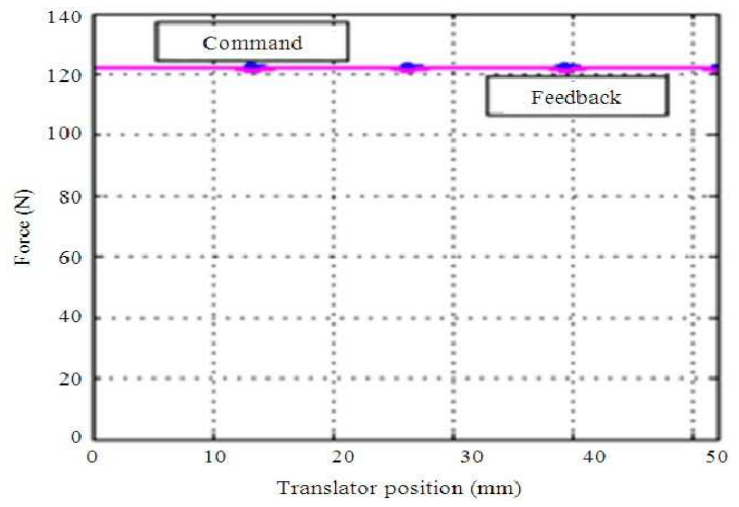

(a) 


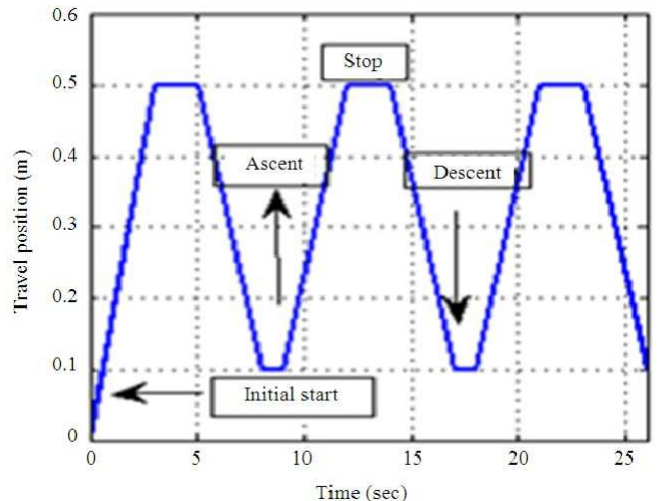

(I)

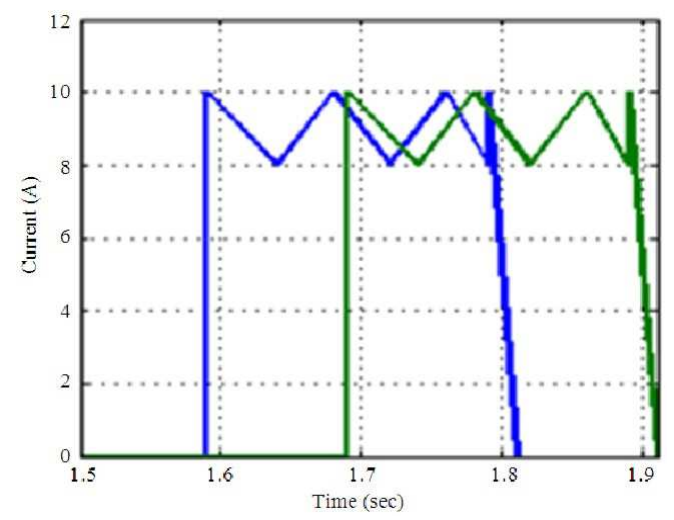

(III)

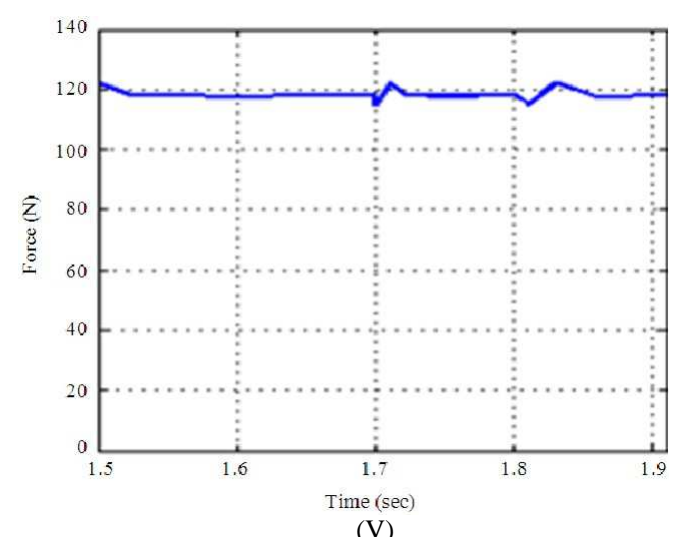

(b)

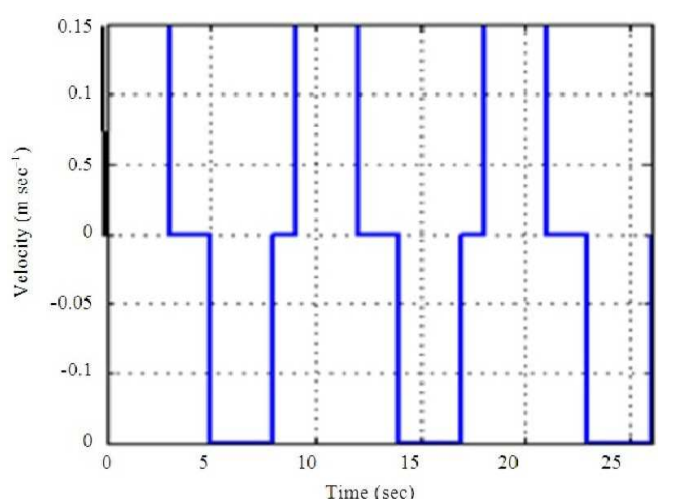

(II)

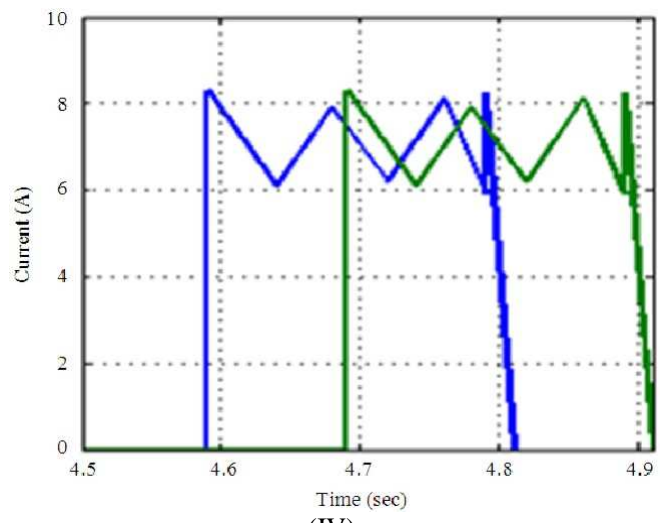

(IV)

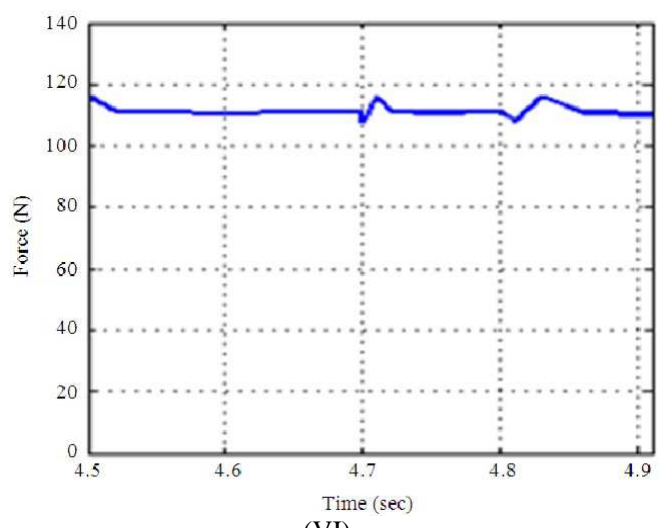

(VI)

Fig. 7: Dynamic analysis (a) Force control; (b) (velocity control; I: control position; II: velocity control; III: phase A and B current during ascent; IV: phase A and B current during descent; V: propulsion force during ascent; VI: propulsion force during descent)

Motor performance for variable load conditions: In practice, motors operate with changing load conditions. The influence of load variation on some of the parameters like the velocity, current and the efficiency of the motor are studied. The results shown in Table 5 are obtained when the circuit is turned $\mathrm{ON}$ at the point when the inductance starts to increase and turned OFF before it starts to decrease.

Figure 8 a shows the velocity and current variation for different load conditions. The velocity steadily decreases with an increase in load. This characteristic reminds of the speed-load characteristic of a series DC motor. 
Am. J. Engg. \& Applied Sci., 3 (2): 433-440, 2010

Table 5: Influence of load on motor performance

\begin{tabular}{lccclc}
\hline $\mathrm{F}_{\mathrm{L}}(\mathrm{N})$ & $\mathrm{I}(\mathrm{A})$ & $\mathrm{V}\left(\mathrm{m} \mathrm{sec}^{-1}\right)$ & $\begin{array}{l}\text { Input } \\
\text { power }(\mathrm{W})\end{array}$ & $\begin{array}{l}\text { Output } \\
\text { power }(\mathrm{W})\end{array}$ & $\begin{array}{l}\text { Efficiency } \\
(\%)\end{array}$ \\
\hline 2 & 2.09 & 10.42 & 57.85 & 26.12 & 45.15 \\
5 & 3.28 & 8.03 & 65.84 & 31.46 & 47.78 \\
10 & 4.72 & 6.40 & 91.39 & 39.00 & 42.67 \\
20 & 5.31 & 4.02 & 114.61 & 46.99 & 41.00 \\
40 & 6.19 & 3.35 & 151.36 & 57.70 & 38.12 \\
60 & 7.87 & 2.65 & 181.32 & 63.66 & 35.11 \\
80 & 8.29 & 1.28 & 196.36 & 67.00 & 34.12 \\
100 & 9.79 & 0.50 & 214.45 & 71.11 & 33.16 \\
120 & 10.5 & 0.15 & 255.84 & 77.80 & 30.41 \\
\hline
\end{tabular}

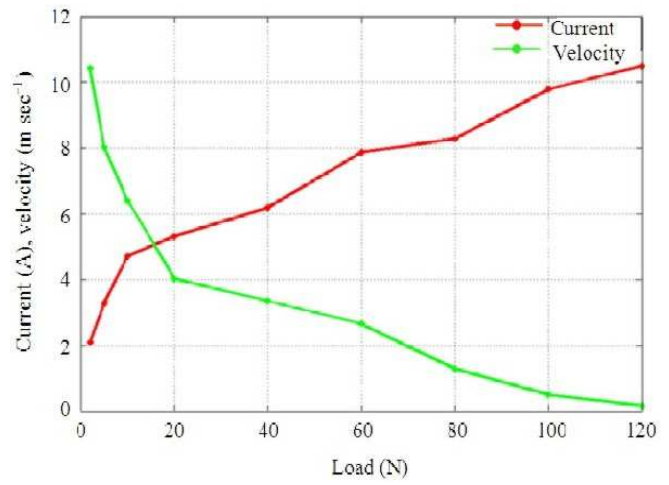

(a)

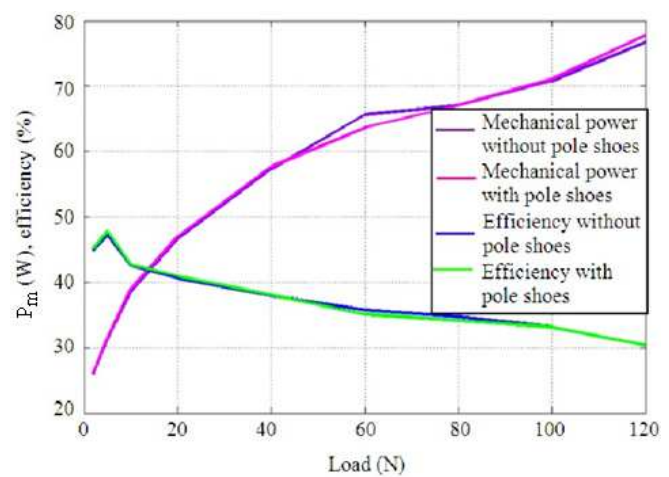

(b)

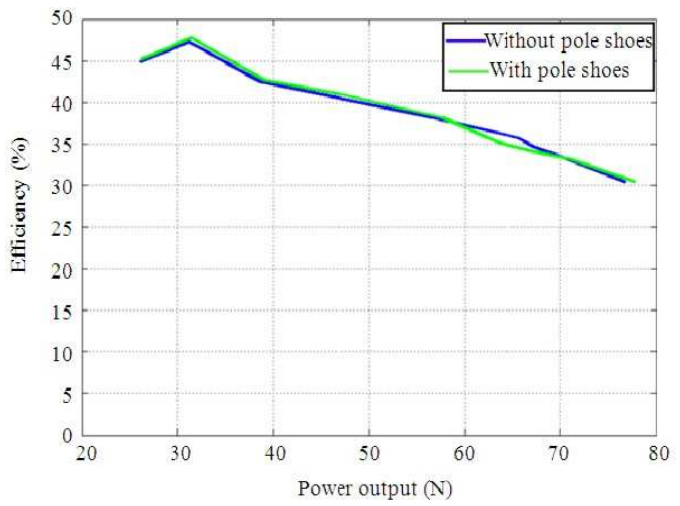

(c)

Fig. 8: (a) Variation of current and velocity with load; (b) Variation of $\mathrm{P}_{\mathrm{m}}$, efficiency with load; (c) Variation of efficiency with $\mathrm{P}_{\mathrm{m}}$
Figure $8 \mathrm{~b}$ shows the characteristics of mechanical power $\mathrm{P}_{\mathrm{m}}$ and the efficiency with change in load. It can be seen that, initially as the load increases the efficiency increases and when load is further increased the efficiency started to decrease. Figure 8c shows the characteristics of the efficiency with change in mechanical power $\mathrm{P}_{\mathrm{m}}$. It can be seen that, the efficiency is high at most cases, encourages the proposal of the pole shoe concept in LSRM.

\section{RESULTS}

Figure 9 shows the actual experimental setup for the prototype LSRM with the stator pole shoe that is used as a material carrying vehicle in the laboratory. The experimental road is $2 \mathrm{~m}$ long and translator weight is $12 \mathrm{~kg}$. It should be noted that the present setup is intended for development purposes only.

The inductance for the different positions at rated current is measured by locking the translator at each position. A constant current is applied to a phase and is turned off and the falling current profile is computed. The time constant is measured from the profile and hence the inductance is calculated. The measured values of inductance are plotted alongside the FEA results in Fig. 10. A comparison of inductance values at aligned and unaligned positions are given in Table 6 at the rated current. Figure 11 shows actual phase voltage and phase current waveforms of the LSRM.

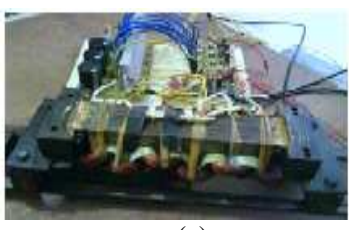

(a)

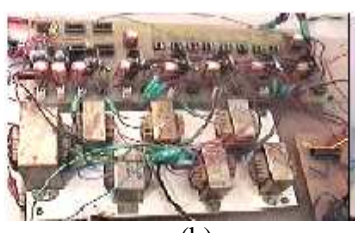

(b)

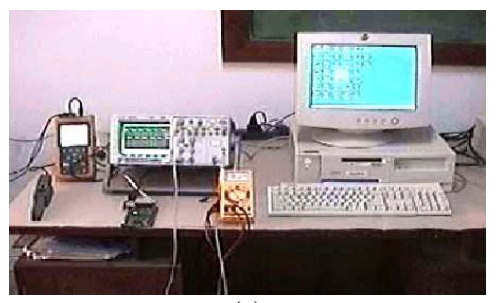

(c)

Fig. 9: Experimental setup of (a) LSRM and converter; (b) Driver circuit; (c) PC along with measuring instruments 


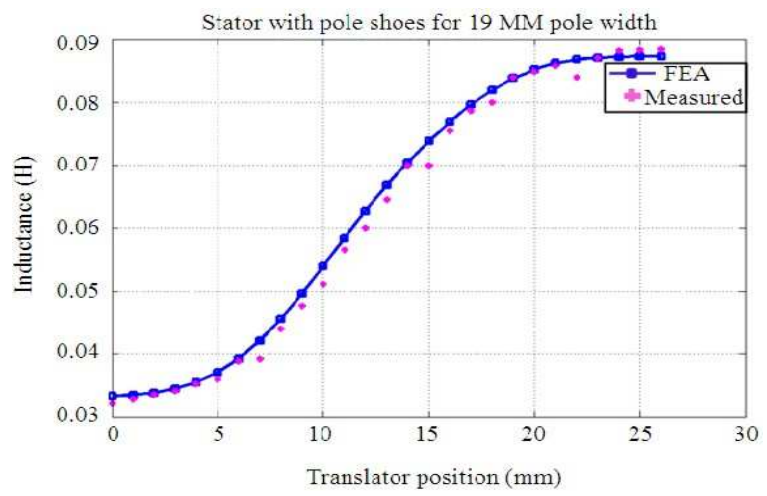

Fig. 10: Comparison of FEA and measured inductance values at rated current

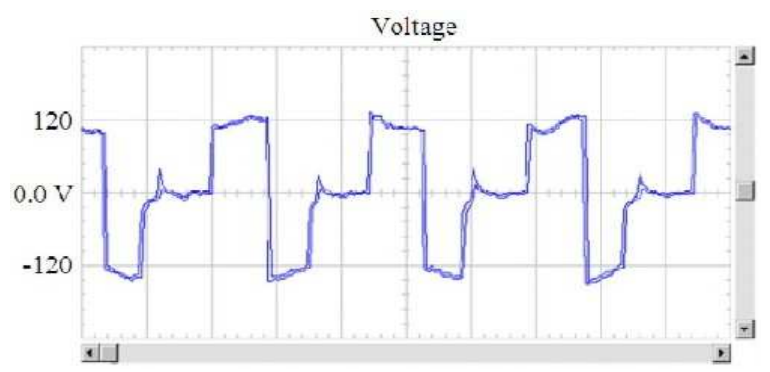

(a)

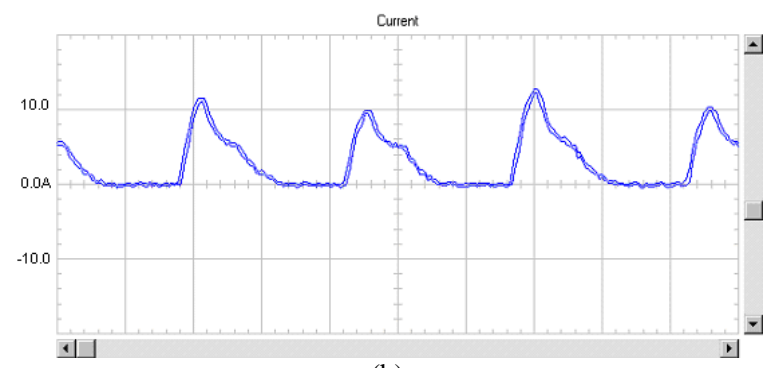

(b)

Fig. 11: Experimental waveforms during single pulse operation (a) actual phase voltage of LSRM; (b) actual phase current of LSRM

Table 6: Comparison of the calculated and the measured inductance at rated current

\begin{tabular}{lll}
\multicolumn{2}{c}{ rated current } & \\
& Inductance $(\mathrm{H})$ & \\
& -------- & Unaligned \\
\hline Method & Aligned & 0.0332 \\
MEA & 0.0873 & 0.0321 \\
\hline
\end{tabular}

\section{DISCUSSION}

The provision of stator pole shoes improves the force profile and reduces the force ripple at the maximum force regions. Hence, the maximum force is allowed to remain the same for more positions of the translator. The extent of the low force region around the unaligned position is reduced due to the addition of pole shoes. From Table 3 it can be observed that, as the stator pole width is increased, keeping the stator pole shoe width as constant, there is a reduction in the average force, which is not large after certain a point. The sensitivity study also depicts that any reduction in the width of the stator pole for the same variations of the pole shoe arcs, contributes to a loss of the average force. It is generally accepted that decreasing the stator pole width will decrease the aligned inductance with negligible effect on the unaligned inductance. This is reflected in Table 2. Finally, from the Table 4 we inferred that, the proposed LSRM (19 mm stator pole width) has high force density, less force ripple and volume when compared to the conventional machine. So only, for the other analysis in this study we prefer LSRM with pole shoe having $19 \mathrm{~mm}$ pole width.

\section{CONCLUSION}

A modification of the stator geometry by the provision of stator pole shoes has been presented. A prototype LSRMs is modeled, simulated, analyzed, developed and experimentally validated with the conventional control strategy. The following conclusions are observed when compared to the conventional machine:

- Force ripple is reduced by $5.44 \%$

- Volume of the stator is reduced by $2.35 \%$

- Mass of the stator is reduced by $2.44 \%$

- Force density is high in the proposed structure

- The maximum efficiency occurs at a load force of $5 \mathrm{~N}$, which is also high when compared to the conventional LSRM

- There is a good agreement between measurement results and FEA values of the inductance profile

The proposed stator pole shoe geometry research can be further extended to study the thermal, stress and vibration analyses.

\section{REFERENCES}

Amoros, J.G. and P. Andrada, 2010. Sensitivity analysis of geometrical parameters on a doublesided linear switched reluctance motor. IEEE Trans. Ind. Elect., 57: 311-319.

Arumugam, R., J.F. Lindsay and R. Krishnan, 1988. Sensitivity of pole arc/pole pitch ratio on switched reluctance motor performance. Proceeding of the Conference Record IEEE IAS Annual Meeting, Oct. 2-7, IEEE Computer Society, Pittsburgh, PA., pp: 50-54. 
Bae, H.K., B.S. Lee, P. Vijayaraghavan and R. Krishnan, 2000. A linear switched reluctance motor: Converter and control. IEEE Trans. Ind. Appli., 36: 1351-1359.

Byeong-Seok, L., B. Han-Kyung, V. Praveen and R. Krishnan, 2000. Design of a linear switched reluctance machine. IEEE Trans. Ind. Appli., 36: $1571-1580$.

Chayopitak, N. and D.G. Taylor, 2005. Design of linear variable reluctance motor using computer-aided design assistant. Proceeding of the IEEE International Conference Elect. Mach. Drives, pp: 1569-1575.

Deshpande, U.S., J.J. Cathey and E. Richter, 1995. High-force density linear switched reluctance machine. IEEE Trans. Ind. Appli., 31: 345-352.

Hussain, I. and M. Ehsani, 1996. Torque Ripple minimization in switched reluctance motor drives by PWM current control. IEEE Trans. Power Elect., 11: 83-88.

Kolomeitsev, L., D. Kraynov, F. Pakhomin, F. Rednov and E. Kallenbach et al., 2008. Linear switched reluctance motor as high efficiency propulsion system for railway vehicles. Proceeding of the SPEEDAM, June 11-13, pp: 155-160.

Lim, H.S. and R. Krishnan, 2007. Ropeless elevator with linear switched reluctance motor drive actuation systems. IEEE Trans. Ind. Elect., 54: 2209-2218.

Lim, H.S., R. Krishnan and N.S. Lobo, 2008. Design and control of a linear propulsion system for an elevator using linear switched reluctance motor drives. IEEE Trans. Ind. Elect., 55: 534-542.
Lobo, N.S., H.S. Lim and R. Krishnan, 2008. Comparison of linear switched reluctance machines for vertical propulsion application: Analysis, design and experimental correlation. IEEE Trans. Ind. Appli., 44: 1134-1142.

Miller, T.J.E., 1993. Switched Reluctance Motor and Their Control. Hillsboro, Magna Phys. OH, ISBN: 0198593872, pp: 200.

Pan, J., N.C. Cheung and J. Yang, 2005. High-precision position control of a novel planar switched reluctance motor. IEEE Trans. Ind. Elect., 52: 1644-1652.

Rabinovici, R., 2005. Torque ripple, vibrations and acoustic noise in switched reluctance motors. HAIT J. Sci. Eng. B., 2: 776-786. http://www.hit.ac.il/jse/B/vol0236B/jse28.pdf

Schramm, D., B.W. Williams and T.C. Green, 1992. Torque ripple reduction of switched reluctance motors by phase current optimal profiling. Proceeding of the IEEE PESC'92, pp: 857-860.

Sun, Z., N.C. Cheung, J. Pan, S.W. Zhao and W.C. Gan, 2008. Design and simulation of a magnetic levitated switched reluctance linear actuator system for high precision application. Proceeding of the IEEE ISIE, June 30-July 2, pp: 624-629. http://158.132.178.85/norbert/Papers/C075.pdf

Zhao, S.W., N.C. Cheung, W.C. Gan, J.M. Yang and J.F. Pan, 2007. A self-tuning regulator for the highprecision position control of a linear switched reluctance motor. IEEE Trans. Ind. Elect., 54: $2425-2434$. 